\title{
The nuclear reproductive cycle in the myxomycetes: a review
}

\section{Clark $\mathbf{J}^{1}$ and Haskins $\mathbf{E F}^{2}$}

${ }^{1}$ Department of Biology, University of Kentucky, Lexington, Kentucky 40506 - jimc1939@ frontier.com

${ }^{2}$ Department of Biology, University of Washington, Seattle, Washington 98195 - edward.haskins@ @omcast.net

Clark J, Haskins EF 2013 - The nuclear reproductive cycle in the myxomycetes: a review. Mycosphere 4(2), 233-248, Doi 10.5943/mycosphere/4/2/6

Our understanding of the taxonomy, ecology and population biology of myxomycetes has been enhanced by investigations of the nuclear reproductive cycle of taxa in this group. These studies have involved light microscopy, electron microscopy, DNA cytophotometric reports and genetic investigations. Heterothallism with its associated life cycle events of syngamy and meiosis is extensively reviewed as revealed by light microscopy, genetics and DNA spectrophotometric analysis of nuclear ploidy levels. Non-heterothallism, i.e., homothallism and apogamy, specifically automixis and its genetical and evolutionary significance is discussed. Nuclear division, chromosomal number and polyploidy in the myxomycetes is also detailed.

Key words - apogamy - automixis - heterothallism - homothallism - myxomycetes - nuclearcycle - polyploidy

\section{Article Information}

Received 11 January 2013

Accepted 30 January 2013

Published online 25 March 2013

Corresponding author: Jim Clark - jimc1939@frontier.com

\section{Introduction}

An understanding of the nuclear reproductive cycle, and its variations, can aid and inform our understanding of the taxonomy, ecology and population biology of myxomycetes. Thus considerable effort has been expended in the study of the occurrence and location of these nuclear cycle events. While several excellent reviews (Gray \& Alexopoulos 1968, Collins 1979, 1981) have covered parts of this area, they are somewhat limited in availability and enough new information has accumulated to warrant an updated review.

In the myxomycetes, the reproductive pattern set out by de Bary (1858) is followed by all known species: small generally windborne spores germinate to release uninucleate amoeboflagellate cells, which are vegetative and can form large populations; these amoeboflagellates then form multi-nucleate vegetative plasmodia which give rise to sporangia to complete the cycle by producing spores. However, while the sequence of stages in the reproductive cycle is consistent from one species and isolate to the next, the nuclear cycle can display considerable variability; that can be divided into two major categories: heterothallism and non-heterothallism (see review by Clark \& Haskins 2010). In the heterothallic group, the amoeboflagellates possess mating types and have a haploiddiploid sexual reproductive cycle, whereas the non-heterothallic group is not known to possess mating types and thus may be either sexual (homothallic) or nonsexual (apogamic). While a nonsexual organism would not have a 
nuclear cycle since there would be no change in ploidy during the reproductive cycle, the occurrence of a haploid/diploid nuclear cycle in a non-heterothallic isolate would indicate that it is homothallic.

A list of reproductive nuclear cycle reports is given in Table I. This list is divided into three groups: group A studies where the heterothallic/non-heterothallic nature of the material was unknown; group B studies where the isolates were known heterothallics; and group $\mathrm{C}$ studies where the isolates were known non-heterothallics. The A group, which consist mainly of earlier studies, displays rather variable results and is probably of limited value since the lack of background information makes it difficult to evaluate the validity and meaning of these results.

Table 1 Reproductive nuclear cycle reports

All names according to Martin \& Alexopoulos (1968)

\section{A. Studies where only cytological information was available}

Arcyria cinerea: karyogamy in plasmodium, and nuclear fusion with meiosis I \& II in spores Kranzlin (1907); synaptinemal complexes in young spores (Aldrich \& Mims 1970).

Arcyria incarnata: a single pre-cleavage division (Lister 1893); synaptinemal complexes in young spores (Aldrich \& Mims 1970).

Badhamia utricularis: a single pre-cleavage division (Lister 1893); a single meiotic pre-cleavage division (Jahn 1933).

Ceratiomyxa fruiticulosa: plasmogamy of swarm cells and karogamy in plasmodia with a single meiotic pre-cleavage division (Jahn 1908); multiple swarm cell plasmogamy and plasmodial karyogamy with meiosis I \& II in spores (Gilbert 1935); meiosis I \& II in spores (Olive 1907); plasmogamy of paired swarm cells (McManus 1958); meiosis I \& II in spores (Wilson \& Ross 1955); syngamy of swarm cells with meiosis I \& II in spores (Sansome \& Sansome 1961, Sansome \& Dixon 1965).
Clastoderma debaryanum: plasmogamy of paired swarm cells (McManus 1961).

Comatricha nigra: a single pre-cleavage division (Lister 1893); meiosis I \& II in spores (von Stosch 1937).

Comatricha typhoides: syngamy of paired swarm cells (Ross 1957); pre-cleavage meiosis I \& II (Wilson \& Ross 1955).

Diachea leucopodia: syngamy of paired swarm cells (Ross 1957).

Dictydiaethalium plumbeum: syngamy of paired swarm cells (Ross 1957).

Dictydium cancellatum: no sporangial division (Jahn 1901); syngamy of paired swarm cells and pre-cleavage meiosis I \& II (Ross 1961).

Didymium clavus: meiosis I \& II in spores (Dangeard 1947).

Didymium difforme: plasmogamy of multiple myxamoebae (Cienkowski 1863a, b); plasmogamy of multiple myxamoebae and karyogamy in plasmodium just prior to sporulation (Skupienski 1926a, b); plasmogamy of paired swarm cells (Cayley 1929).

Didymium iridis (includes all D. nigripes): syngamy of paired myxamoebae with pre-cleavage meiosis I \& II (Cadman 1931); plasmogamy of paired myxamoebae and karyogamy in plasmodium just prior to sporulation (Schünemann 1930).

Didymium melanospermum: a single precleavage division (Harper 1914).

Didymium squamulosum: syngamy of paired myxamoebae (Ross 1957).

Enteridium rozeanum: syngamy of paired swarm cells (Ross 1957).

Enteridium sp. (Reticularia): a single precleavage division (Harper 1914).

Fuligo septica: a single pre-cleavage division (Harper 1914, Rosen 1893); syngamy of paired swarm cells with pre-cleavage meiosis I \& II (Ross 1961).

Hemitrichia stipitata: synaptinemal complexes in young spores (Aldrich \& Mims 1970).

Lamproderma arcyriodes: syngamy of paired swarm cells with pre-cleavage meiosis I \& II (Ross 1960).

Lamproderma arcyrionema: pre-cleavage meiosis I \& II (Wilson \& Ross 1955). 
Lycogala epidendrum: syngamy of paired swarm cells (Ross 1957); a single precleavage division (Harper 1914); precleavage meiosis I \& II (Wilson \& Ross 1955).

Lycogala exiguum: a single pre-cleavage division (Conrad 1910).

Metatrichia vesparium (Hemitrichia vesparium): syngamy of paired swarm cells (Ross 1957); pre-cleavage meiosis I \& II (Wilson \& Ross 1955).

Mucilago crustacean: pre-cleavage meiosis I \& II (Schure 1949).

Perichaena vermicularis: pre-cleavage meiosis I \& II or in spores depending upon sporulation conditions (Ross 1967b).

Physarella oblonga: a single pre-cleavage division (Bisby 1914); syngamy of paired myxamoebae with pre-cleavage meiosis I \& II (Ross 1961).

Physarum bogoriense: synaptinemal complexes in young spores (Aldrich \& Mims 1970).

Physarum cinereum: synaptinemal complexes in young spores (Aldrich \& Mims 1970).

Physarum didermoides: syngamy of paired myxamoebae with one possible precleavage meiotic division (Jahn 1911); one pre-cleavage division (Schure 1949).

Physarum gyrosum: syngamy of myxamoebae and or swarm cells with pre-cleavage division figures (Koevenig 1964).

Physarum leucophaeum: a single pre-cleavage division (Lister 1893).

Physarum oblatum: syngamy of paired myxamoebae cells (Ross 1957).

Physarum polycephalum: syngamy of swarm cells with a single pre-cleavage division (Howard 1931); a single precleavage division (Dalleux 1940); syngamy of swarm cells with precleavage meiosis I \& II (Ross 1961).

Physarum psittacinum: karyogamy in plasmodium (Prowazek 1904).

Reticularia lycoperdon: syngamy of paired swarm cells with pre-cleavage meiosis I \& II (Wilson \& Cadman 1928).

Stemonitis axifera: syngamy of paired swarm cells (Ross 1957).
Stemonitis flavogenita: plasmogamy of myxamoebae and or swarm cells (Koevenig 1961, 1964).

Stemonitis fusca: plasmogamy between a myxamoeba and a swarm cell (McManus 1961, Benedict 1962); a single pre-cleavage division (Bisby 1914); pre-cleavage meiosis I \& II (Koevenig 1964); syngamy of paired swarm cells (Ross 1957).

Stemonitis herbatica: syngamy of paired swarm cells (Ross 1957); synaptinemal complexes in young spores (Aldrich \& Mims 1970).

Stemonitis pallida: pre-cleavage meiosis I \& II (Wilson \& Ross 1955).

Stemonitis nigrescens: syngamy of paired swarm cells (Ross 1957).

Trichia botrytis (fragilis): a single pre-cleavage division (Lister 1893).

Trichia persimilis: nuclear fusion in sporangium with meiosis I \& II at spore germination (Kranzlin 1907); syngamy of paired swarm cells (Ross 1957); precleavage meiosis I \& II (Wilson \& Ross 1955).

Trichia decipiens (fallax): a single precleavage division (Strasburger 1884); nuclear fusion in sporangium with meiosis I \& II at spore germination (Kranzlin 1907); a single pre cleavage division (Lister 1893).

Trichia varia: a single pre-cleavage division (Jahn 1933).

Tubifera ferruginosa: synaptinemal complexes in young spores (Aldrich \& Mims 1970).

Tubifera microsperma: pre-cleavage meiosis I \& II (Ross 1961).

\section{B. Studies involving known heterothallic isolates}

Didymium iridis (including all D. nigripes): syngamy of paired swarm cells with meiosis I \& II in spores (von Stosch 1935); microspectrophotometry showing pre-cleavage meiosis I \& II (Therrien 1966); syngamy of myxamoebae (Ross 1967a).

CR 5 strain: microspectrophotometry of DNA levels in amoeboflagellates and 
plasmodium indicated a haploid/diploid cycle (Collins \& Therrien 1976).

CR 25 strain: microspectrophotometry of DNA levels in amoeboflagellates and plasmodium indicated a haploid/diploid cycle with polyploidy in one amoeboflagellate clone (Collins \& Therrien 1976).

Hon 1 strain: pre-cleavage synaptinemal complexes (Carroll \& Dykstra 1966); synaptinemal complexes in young spores (Aldrich \& Carroll 1991) with Carroll and Dykstra's report probably due to abnormal cleavage (examined old blocks); microspectrophotometry of DNA levels in amoeboflagellates and plasmodium indicated a haploid/diploid cycle (Collins \& Therrien 1976).

Ky 1 strain: microspectrophotometry of DNA levels in amoeboflagellates and plasmodium indicated a haploid/diploid cycle (Collins \& Therrien 1976).

Pan 1 strain: microspectrophotometry of DNA levels in amoeboflagellates and plasmodium indicated a haploid/diploid cycle (Collins \& Therrien 1976).

Pan 2 strain: microspectrophotometry of DNA levels in amoeboflagellates and plasmodium indicated a haploid/diploid cycle (Collins \& Therrien 1976).

Pan 3 strain: microspectrophotometry of DNA levels in amoeboflagellates and plasmodium indicated a haploid/diploid cycle with polyploidy in one amoeboflagellate clone (Collins \& Therrien 1976).

Physarum flavicomum: meiosis I \& II with synaptinemal complexes in young spores with some disintegrating nuclei (Aldrich 1976); microspectrophotometry showing pre-cleavage meiosis I \& II (Therrien 1966).

Physarum globuliferum: synaptinemal complexes in young spores (Aldrich 1976).

Physarum polycephalum: plasmogamy and karyogamy occurs between any two myxamoebae but plasmodial differentiation only occurs when they are heteroallelic for mating type (Bailey et al. 1990); one meiotic pre-cleavage division (Guttes et al. 1961); meiosis in spores (von Stosch et al. 1964); synaptinemal complexes in young spores (Aldrich 1967); light microscopy, electron microscopy and microphotospectrometry determinations found a basic pattern of meiosis in young spores with all but one resulting nucleus disintegrating, but there were considerable variation in the details including some pre-cleavage meiosis (Laane \& Haugli 1976).

Physarum pusillum microphotospectrometry showing pre-cleavage meiosis I \& II (Therrien 1966).

\section{Studies involving known non- heterothallic isolates}

Didymium difforme: pre-cleavage meiosis I with meiosis II at spore germination (Cayley 1929).

Didymium iridis (including all D. nigripes): possible pre-cleavage meiosis I \& II figures (Schünemann 1930) and precleavage figures in same isolate (von Stosch 1935).

Kerr's strain: plasmogamy of paired swarm cells (Kerr 1961); microspectrophotometry indicated haploid amoebae and diploid zygotes (Therrien 1966); presumed pre-cleavage meiotic figures with no synaptinemal complexes (Schuster 1964).

Cal 1 strain: microspectrophotometry of DNA levels in amoeboflagellates and plasmodium indicating a haploiddiploid cycle (Collins \& Therrien 1976).

Ga 1 strain: microspectrophotometry of DNA levels in amoeboflagellates and plasmodium indicating a diploid/diploid cycle (Collins \& Therrien 1976).

Ha 1 strain: microspectrophotometry of DNA levels in amoeboflagellates and plasmodium indicating a diploid/diploid cycle with polyploidy (Collins \& Therrien 1976).

Mo 1 strain: microspectrophotometry of DNA levels in amoeboflagellates and plasmodium indicating a haploiddiploid cycle (Collins \& Therrien 1976); synaptinemal complexes in young spores (Sherman \& Mims 1985). 
Pan 1 strain: microspectrophotomertry of DNA found heterothallic mating type amoebal clones and diploid plasmodial forming lines (Yemma et al. 1983).

Pan 4 strain: microspectrophotometry of DNA levels in amoeboflagellates and plasmodium indicating a haploiddiploid cycle (Collins \& Therrien 1976) however (Collins 1980, Collins et al. 1983, Collins \& Gong 1985) found that this strain contained both plasmodial forming diploid amoeboflagellates and haploid amoeboflagellates with two different mating types (an apparent conversion from the diploid strain during long term clonal culture).

Pan 5 strain: microspectrophotometry of DNA levels in amoeboflagellates and plasmodium indicating a haploiddiploid cycle (Collins \& Therrien 1976).

Ph-1 strain: microspectrophotometry of DNA levels in amoeboflagellates and plasmodium indicating a diploid/diploid cycle (Therrien \& Yemma 1974); haploid sexual clones isolated from the apogamic strain (Yemma et al. 1980); synaptinemal complexes in young spores (Aldrich \& Carroll 1971).

Didymium squamulosum: pre-cleavage division (von Stosch 1937).

Echinostelium minutum: microspectrophotometry of DNA levels in amoeboflagellates and plasmodium indicating a diploid/diploid cycle with polyploidy in one line (Haskins \& Therrien 1978); synaptinemal complexes in young spores (Haskins et al. 1971); microspectrophotometry of a division within the developing spore did not show the reduction in DNA levels expected during meiosis (Therrien \& Haskins 1981).

Physarum cinereum: a single pre-cleavage division (von Stosch 1935).

Physarum pusillum: synaptinemal complexes in young spores (Aldrich \& Mims 1970).

Stemonitis flavogenita: synaptinemal complexes in young spores of the CR-1 strain (Gaither \& Collins 1984), cytophotometric studies of this strain, which normally displayed a diploiddiploid amoeboflagellate plasmodium cycle, found haploid amoeboid clones (Collins \& Tang 1988) which were produced during vegetative growth, that had mating types and could fuse to form diploid plasmodia (Collins et al. 1983a).

\section{Heterothallism}

Heterothallic myxomycete isolates have a sexual cycle in which the haploid amoeboflagellate stage undergoes syngamy to produce a diploid zygotic cell that develops into a diploid plasmodium. Functional syngamy with the production of a diploid plasmodium requires that the two amoeboflagellate cells involved, each carry a different allele of the multiple allelic system (Collins 1963). During sporulation the diploid nuclei undergo meiosis in the young developing spores and each haploid nucleus receives one of the mating type alleles (Collins 1961).

\section{Syngamy}

Syngamy, in the myxomycetes, consists of two related events, plasmogamy (the fusion of the gametic cells prior to nuclear fusion) and karyogamy (the fusion of the haploid nuclei to form the diploid zygotic nucleus), and was reported to occur between two amoeboflagellates in several very early studies. However, considerable controversy occurred in regards to the number of amoeboflagellates involved and their state (myxamoebae or flagellate swarm cells) at the time of syngamy. Several reports indicated that plasmogamy involved the possible coalescence of a number of myxamoebae prior to plasmodial formation (Cienkowski 1863a, b, Skupienski 1926a, b, Wilson \& Cadman 1928, Gilbert 1935, Wollman 1966), while others (Jahn 1911, Cayley 1929, Schünemann 1930, McManus 1961) reported only paired fusions. There were also differing reports of plasmogamy occurring only between myxamoebae (Jahn 1911), only between swarm cells (Wilson \& Cadman 1928, Howard 1931, von Stosch 1935, McManus 1961) or between either (Ross 1957, Koevenig 1961, 1964, Kerr 1961). These early studies also generally reported that karyogamy 
occurred shortly after plamogamy (Jahn 1911, Wilson \& Cadman 1928, Cadman 1931, Howard 1931, von Stosch 1935, Gilbert 1935, Ross 1957, Koevenig 1961), although others reported that karyogamy was delayed and occurred in the plasmodium (Prowazek 1904, Olive 1907, Kranzlin 1907, Jahn 1908, Skupienski 1926, 1927, Schünemann 1930). However, by the end of this early period, a general consensus, relying heavily on careful studies by Ross and Koevenig, considered that sexual myxomycetes underwent plasmogamy between myxamoebae or swarm cells in pairs with some species favoring one method, but most employing either according to circumstances, and that karyogamy occurred shortly after plasmogamy.

The discovery of sexual heterothallism in Didymium iridis (Collins 1961) and Physarum polycephalum (Dee 1960) opened up a new avenue for syngamy research in the myxomycetes since it allowed researchers to make controlled crosses of known sexual strains. Ross (1967) using a heterothallic strain of Didymium iridis confirmed the general consensus arrived at by the earlier studies; and with others (Ross \& Cummings 1970, Ross \& Shipley 1973, Albert \& Therrien 1985) went on to show that amoeboflagellates must first become competent before they can fuse and that competency required that the cells reach a minimum population density. Both Didymium iridis and Pysarum polycephalum mating type amoeboflagellate clones were grown separately (Shipley \& Holt 1982) to the competency density before mixing, to demonstrate that both mating types must be competent before syngamy would occur and that competency involved the production of an extracellular inducer material released by the growing amoeboflagellates (Youngman et al. 1977, Pallotta et al. 1979, Nader et al. 1984, Albert \& Therrien 1985). Ross \& Cummings (1970) also observed that the mixing of mating type clones after they had reached maximum competency, produced a rapid fusion of multiple amoeboflagellates that formed polyploid nuclei in large synctia. This behavior, under very artificial conditions, would explain the occasional observations of multiple cell fusions observed in earlier studies. The fate of these polyploid nuclei was examined in Didymium iridis by Clark (1984) using three clones carrying different plasmodial incompatibility genes (see review by Clark \& Haskins 2011). These clones were selected so that a plasmodium resulting from a multiple fusion event would display a particular plasmodial fusion phenotype only if genetic information from all three clones were present. The resulting plasmodia often carried this phenotype, but over a period of time in culture the plasmodia generally changed to a different phenotype (apparently the polypoid nuclei shed some chromosomes).

Time-lapse micro-cinematography of live immunofluorescence stained amoeboflagellates of Physarum polycephalum (Bailet et al. 1990) showed that the mating locus controlled plasmodial differentiation and not cell or nuclear fusion. Apparently any two competent amoeboflagellates can undergo plasmogamy and karygamy, but plasmodial form only in the mating type heteroallelic pairings, while the fused cells and nuclei of the homoallelic pairings apparently separate or degenerate without forming plasmodia. However, there may be rare cases of illegitimate plasmodial formation involving homoallelic pairings since clonal mating-type isolates will occasionally produce plasmodia without crossing (Collins \& Ling 1968, Anderson \& Truitt 1983). Termed selfing, these plasmodia are haploid (Yemma \& Therrien 1972) and grow poorly, but will sometimes sporulate to produce amoeboflagellates having only the original mating type (thus they are not due to some type of accidental contamination mating). The Colonia isolate of Physarum polycephalum is an extreme example of this selfing behavior; in this isolate clonal amoeboflagellate populations have mating types and cross (Poulter \& Honey 1977) to produce diploid plasmodia, but they can also produce haploid plasmodia when they have no mating partner (Cooke \& Dee 1974, Anderson et al. 1976, Mohberg 1977). During this process, some haploid cells undergo an extended cell cycle during which they become committed and gain plasmodial characteristics (Bailey 1995). Therefore, the Colonia isolate is heterothallic and faculatively apomictic and not homothallic as it is often designated. Thus, syngamy in the myxomycetes, as presently 
understood, occurs between pairs of competent amoeboflagellates with karyogamy following plasmogamy, however plasmodial differentiation, in general, only occurs when the amoeboflallates are heteroallelic for the mating locus. While this sexual fusion usually results in a diploid plasmodial nucleus, multiple cell fusions can occur under some unusual circumstances to produce generally temporary polyploidy nuclei. While the many reports of plamogamy and karyogamy (Table I) may serve to indicate a possible sexual cycle in those species and isolates, by themselves, they cannot serve as a definitive proof of sexuality, since this requires evidence of a syngamy which produces a diploid nucleus that undergoes genetic segregation.

\section{Meiosis}

Meiosis consists of two connected nuclear divisions that reduce the chromosome number by one half. In meiosis I the chromosomes replicate, pair, undergo crossing over and then separate into separate nuclei; the replicated chromosomes then divide during meiosis II. Unfortunately, in the myxomycetes, the nuclei and chromosomes are extremely minute and adequate cytological preparations and chromosome counts are difficult to obtain. Thus early investigators had to rely on estimated chromosome counts and the occurrence of two nuclear divisions where apparent chromosome bridges or rings occur in the first division. Later workers were able to utilize several additional techniques such as electron microscopy and DNA spectrophotomectrics. Synaptinemal complexes, seen in electron micrographs, are generally found only with paired chromosomes and are thus evidence for the occurrence of division I of meiosis (Moses \& Coleman 1964). Also, careful comparative DNA level studies of the nuclei of different life cycle stages, determined by spectrophotometrics, can be used to replace or supplement chromosome counts.

While almost all researchers agree (Table I) that meiosis takes place during sporulation, there is considerable disagreement among workers on whether it precedes or follows spore cleavage. The three conclusions of the different researchers are that meiosis occurs prior to spore cleavage, meiosis occurs in the cleaved spores, or meiosis occurs in the mature spores just prior to germination. However, since only Kranzlin (1907) and to a certain extent Cayley (1929) supported the mature spore model, the major disagreement involves whether meiosis occurs before or after spore cleavage. Light microscopic cytological studies supported both the pre-cleavage (Jahn 1908, 1933, Wilson \& Cadman 1925, Schünemann 1930, Cadman 1931, Schure 1949, Wilson \& Ross 1955, Kovenig 1964, Ross 1967a) and post-cleavage spore models (Olive 1907, Gilbert 1935, von Stosch 1935, 1937, Gilbert 1947, Wilson \& Ross 1955, Sansome \& Sansome 1961, Sansome \& Dixon 1963, von Stosch et al. 1967). However, Ross, a major proponent of the pre-cleavage model, also reported that he could shift the site of meiosis from pre to post-cleavage in Perichaena vermicularis by changing the sporulation conditions (Ross 1967b).

DNA spectrophotometric studies, in known heterothallic isolates, supports a haploid ameoboflagellate diploid plasmodium nuclear cycle in Didymium iridis (Collins \& Therrien 1979), Physarum pussillum (Therrien 1966), $P$. flavicomum (Therrien 1966), P. polycephalum (Cooke \& Dee 1974, Laane \& Haughi 1976), and Stemonitis flavogenita (Collins \& Tang 1988). Therrien (1966) also found DNA spectrophotometric evidence for pre-cleavage meiosis in the Didymium iridis, Physarum flavicomum and $P$. pussilum isolates. However, all electron microscopic studies on known heterothallic isolates have found synaptinemal complexes and other evidence of meiosis, only in the developing spores: Physarum flavicomum (Aldrich 1967) using the same isolate studied by Therrien, $P$. gyrosum (Aldrich 1967), P. polcephalum (Aldrich 1967), and Didymium iridis (Aldrich \& Carroll 1991). An earlier study on Didymium iridis by Carroll \& Dykstra (1966) which reported a precleavage meiosis, was re-investigated by Aldrich \& Carroll (1991) and was found to be due to an abnormal cleavage in the material used. In a study using coordinated light and electron microscopy, Laane \& Haugli (1976) reported that Physarum polycephalum displayed a basic system with meiosis in the young spores with all but one of the resulting nuclei degenerating; however, many minor 
variations occurred, including some precleavage meiosis and delayed nuclei degeneration. Since Aldrich (1967) was unable, in his studies, to modify the site of meiosis, by manipulating the environmental conditions during sporulations, a controversy still remains as to the exact site of meiosis. However, the preponderance of evidence would seem to indicate that meiosis occurs during the development of the young spore and that three of the products of the meiosis degenerate to leave the spore uninucleate and haploid (Aldrich 1967, Laane \& Haughi 1970), although later mitotic divisions may produce multinucleate spores.

\section{Non-heterothallism}

Cytophotometric DNA studies and electron microscopy seemed to have solved the puzzle concerning homothallism or apogamy in the non-heterothallic isolates of myxomycetes: some appeared to be homothallic and others apogamic. Cytophotometric studies of seven Didymium iridis isolates (Therrien \& Yemma 1974, Therrien et al. 1977) reported a haploid amoeboflagellate diploid plasmodial cycle in four isolates (Cal 1, Mo 1, Pan 4, Pan 5) and a diploid/diploid cycle in three other isolates $(\mathrm{Ga}$ 1, Ha 1, Ph 1). Diploid/diploid cycles have also been demonstrated in Stemonitis flavogenita strain CR 1 (Collins et al. 1983a) and Echinostelium minutum (Haskins \& Therrien 1978). Also an electron microscope study (Sherman \& Mims 1985) of the Mo 1 isolate of Didymium iridis, determined that synaptinemal complexes occurred in this isolate during spore formation. Thus, there appeared to be reasonable data that confirmed that homothallism occurred in some nonheterothalic isolates (Therrien et al. 1977, Sherman \& Mims 1985). However, synaptinemal complexes were also unexpectedly found in the presumably apogamic Didymium iridis $\mathrm{Ph} 1$ isolate (Aldrich \& Carroll 1971), the Stemonitis flavogenita CR 1 isolate (Gaither \& Collins 1984), the Echinostelium mimutum isolate (Haskins et al. 1971) and a Physarum pusillum isolate (Aldrich \& Mims 1970). Also, a number of non-heterothallic isolates were discovered that reverted to heterothallism (Collins \& Therrien 1976, Collins 1980, Collins et al. 1983a, b,
Collins \& Gong 1985, Collins \& Tang 1988, Yemma et al. 1980) which added to the puzzle. However, these convertants also provided a solution to the puzzle, since the most reasonable explanation of the reversion to heterothallism is that the original isolates were automictic. Since there are no generally accepted definitions of automixis and related terms (Maynard Smith 1978, Mogie 1986), we will use the following description in regards to the myxomycetes; in automixis the diploid nucleus in the spores undergo division I of meiosis (synaptinemal complexes present), but the second division is suppressed to produce two diploid nuclei, or division II occurs with the immediate fusion of sister pro-nuclei to regenerate diploid nuclei. While there is no direct evidence, in myxomycetes, for the occurrence of sister pro-nuclei fusion, there is good evidence for the suppression of division II in Echinostelium minutum (Therrien \& Haskins 1981). Although either process would retain some heterozygous loci during a particular division, the line would soon become homozygous after a few generations due to inbreeding. Thus, the line would produce genetically identical diploid nuclei in all of its spores, which then directly produces identical diploid plasmodia. In morphologically complex organisms (most animals) with separate sexes, anisogametes, and a diploid only life cycle, automixis has serious difficulties, since it must occur by parthenogenesis in the female egg (sperm cannot differentiate) and the resulting initial homozygousity often produces a homozygous recessive lethal condition (the recessive lethal alleles are normally protected by heterozygousity). However, the myxomycetes with isogametes and an alteration of haploid and diploid vegetative stages, avoid many of the problems of automixis; recessive lethal alleles are generally selected against in the haploid phase and any diploid spore is capable of developing into the next stage

The apparent homothallism, in some isolates having haploid DNA levels in their amoeboflagellates (Therrien et al. 1977) could be explained as revertant cultures. All of the non-heterothallic isolates, showing a haploiddiploid cycle, that were studied were long term cultures, and unfortunately were not re-cloned from single amoebae just prior to DNA 
determinations, thus the possibility of mixed revertant amoeboflagellate cultures cannot be dismissed. In a mixed culture the haploid form would be more prevalent since they grow faster and in the large clonal populations studied only a few diploids would be needed to produce the non-heterothallic results, or the haploids could have functional mating types and cross to produce plasmodia. Therefore to demonstrate homothallism, in the myxomycetes, one would need to find haploid amoeboflagellates and diploid plasmodia in an isolate recently isolated from a single amoeba.

Betterley \& Collins' (1983) studied 32 non-heterothallic isolates of Didymium iridis, and found: that they were all genetically different except for several isolates that were collected in the same area. In addition, all of the spores from an isolate were genetically identical, and all attempts to inbreed these isolated among themselves or with heterothallic isolates failed, also supported the automictic model of non-heterothallism. While it appears that automixis is the major cause of non-heterothallism, the occurrence of strict apomixes (as seen in the haploid selfing of heterothallic clones) or homothallism cannot be ruled out as a minor cause of nonheterothallism. Non-heterothallism could also occur due to the inclusion of several meiotic products carrying different mating types in the same spore. However, while multinucleate spores, carrying one, two or four nuclei have been reported to occur in many species of myxomycetes (see review in Gray \& Alexopoulos 1968), the expected mix of selffertile and self-sterile spores has not been reported (Clark \& Haskins 2010). Therefore, the most likely cause of these multinucleate spores would be mitotic nuclear division, or in the case of automixis both of the two identical diploid nuclei surviving in the spore. While automixis involves an abbreviated meiosis, no haploid gametic stage is produced, and thus this form of reproduction, using a broad definition, can be termed apogamic. Although non-heterothallic automicts are certainly derived from normal heterothallic isolates, and while some of them can revert back to heterothallism, it is highly likely that other automicts have accumulated genetic and chromosomal abnormalities which would interfere with their reversion to heterothallism (Collins et al. 1983).

\section{Nuclear division, chromosome number and polyploidy}

As far as it is known, mitotic nuclear division in the uninucleate myxamoebae stage is astral in type with a centriole at each pole and the nuclear membrane breaking down in late prophase (Koevenig 1964, Kerr 1967, Ross 1967, Aldrich 1969, Hinchee \& Haskins 1980a). On the other hand, the synchronous mitotic divisions in the multinucleate plasmodial stage lack centrioles and the nuclear membrane does not break down during mitosis (Kerr 1976, Guttes et al. 1968, Hinchee \& Haskins 1980b). Meiotic nuclear divisions are also intra-membranous and lack centrioles (Aldrich 1969).

The presumed haploid chromosome numbers reported for over 25 different species of myxomycetes (see review by Collins 1979) vary from 4 to 90 and they can vary widely for the same species: 4 to 81 for Didymium iridis, 6 to 87 for Fuligo septica, and 8 to 90 for Physarum polycephalum. Therefore, these light microscope determinations are unreliable due to the small sizes of the nuclei and the chromosomes which can cause very difficult technical problems (Mohberg 1977). This difficulty is well illustrated by Haskins (1976) who required the use of high voltage EM of serial sections to determine that there were 124 chromosomes in the plasmodial nuclei of Echinostelium minutum. Thus, reported chromosome numbers are generally more of an approximation that an actual count.

Early reports of polyploidy in the myxomycetes were also based on light microscope chromosome counts (von Stosch 1935, Wilson \& Ross 1955), which were rather difficult and unreliable due to their small size. However, more recent studies have utilized spectrophotometric measurements of DNA levels and genetic studies as well as the more classic light microscopic techniques. These studies have confirmed that polyploidy occurs in Physarum polycephalum (Alder \& Holt 1975, Mohberg 1977), Didymium iridis (Collins \& Therrien 1976, Mulleavy \& Collins 1979) and Echinostelium mimutum (Haskins 1976) and that it is fairly common. The 
occurrence of these polyploids is, no doubt, part of the reason for the variable chromosome counts that have been reported in the literature for the same species. Polyploidy is especially evident in myxomycetes that have been cultured for any extended period of time; for example, high-resolution flow cytometry (Kubbies et al. 1986) on various cultured strains of Physarum polycephalum found a high degree of genomic size variations between strains and mixoploidy (nuclei of multiple ploidy levels) within the strains.

Mulleavy (1979, Mulleavy \& Collins 1981), using myxamoebal size as in indicator, was able to isolate naturally occurring and chemically induced $\mathrm{N}, 2 \mathrm{~N}, 4 \mathrm{~N}$ and $8 \mathrm{~N}$ amoeboflagellate clones from Didymium iridis mating type cultures. These polyploidy clonal lines retained the ability to mate and produce plasmodia when crossed to the appropriate mating type. Crosses of a diploid myxamoebae clone carrying two $\mathrm{A}^{1}$ mating types with one carrying two $\mathrm{A}^{5}$ mating types produced tetraploid plasmodia which displayed the expected tetraploid ratio of $1 \mathrm{~A}^{1} \mathrm{~A}^{1}: 4 \mathrm{~A}^{1} \mathrm{~A}^{5}: 1$ $A^{5} A^{5}$ after sporulation. The $A^{1} A^{1}$ and $A^{5} A^{5}$ myxamoebae clones were self-sterile and crossed with other appropriate mating type clones. The $\mathrm{A}^{1} \mathrm{~A}^{5}$ clones, on the other hand, produced plasmodia without the need for crossing. Thus, they behaved like nonheterothallics, however, this was only temporary since these diploid plasmodia produced normal haploid clones after sporulation (Mulleavy \& Collins 1979). However, not all crosses produced plasmodia that segregated normally. When a particular polyploid clone (CR 2-25) was crossed to haploid clones the resulting plasmodium produced polyploid plasmodia which shed many of its chromosomes and these ended up with different DNA levels ranging from haploid to the maximum expected polyploidy level of the cross (Therrien \& Collins 1976, Collins et al. 1978). Polyploidy, with the uncovering of lethal alleles during segregation could also explain the occurrence of skewed mating type segregation ratios reported in a number of other Didymium iridis isolates (Clark \& Landolt 1993) and in Comatricha lurida (McGuinness \& Haskins 1985). When plasmodia having an original tetraploid chromosome and DNA level (derived from crossing two $2 \mathrm{~N}$ clones) were followed from plasmodial formation to senescence, it could be shown that there was a general lost of DNA over time till the $2 \mathrm{~N}$ level was reached, but that during senescence there was a new increase in polyploidy levels (Clark 1989). This increase in polyploidy starting just prior to senescence is probably a reflection of a general loss of plasmodial controls at this time (Clark \& Hakim 1980, McCullough et al. 1973). Although polyploidy seems to be rather common in the myxomycetes, there appears to be mechanisms which control or alleviate the problems produced by these extra chromosomes.

\section{Summary}

The small sizes of the nuclei and chromosomes, and the frequent occurrence of polyploidy has made cytology rather difficult in the myxomyetes. However, much progress has been made and we now have the information needed to understand their nuclear reproductive cycle. The cycle in the heterothallic myxomycetes appears complicated, due to the alternation of the amoeboflagellate and plasmodial vegetative stages, but, in general, it is a standard cycle with a number of generally minor variations. Amoeboflagellates become competent to function as gametes when they reach a critical density and produce an extracellular inducer factor. Apparently, any amoeboflagellate that is competent can undergo plasmogamy and karyogamy with any other competent amoeboflagellate, but true syngamy only occurs when the two amoeboflagellates are heteroallelic for mating types; since these heteroallelic fusion develop into diploid plasmodia, while homoallelic pairings and their fused nuclei either separate or undergo degeneration. In the heterothallic myxomycetes, meiosis occurs in the young developing spores, although there appears to be some possible variation in the timing such that pre-cleavage meiosis may also occur. In any case, degeneration of three of the meiotic nuclear products apparently occurs to leave the spore uninucleate and haploid (later mitotic divisions may produce multinucleate spores). 
On the other hand, non-heterothallic reproduction seemed quite confusing since, without knowledge of the nuclear cycle during reproduction, it was impossible to determine if the isolates were homothallic or apogamic. However, enough information has now accumulated to provide a basic hypothesis. Most, if not all, non-heterothallics are automicts in which meiosis I occur in the developing spore (or possibly pre-cleavage), but meiosis II does not take place, thus leaving the spore diploid and uninucleate after one of the nuclei degenerates (multinucleate spores could occur due to both nuclei surviving or by mitotic division in the mature spore), or sister pro-nuclei fuse during meiosis II to produce diploid spores. Since, automixis is a form of apogamy (broadly defined), it appears that most, if not all, non-heterothallic isolates are apogamic.

\section{Discussion}

Since, both sexual heterothallism and automictic reproduction occurs in different isolates of the same species, it raises the question; how is this situation maintained. Although, all isolates of Echinostelium minutum collected in temperate environments have been found to be non-heterothallic, and all of those from arid deserts heterothallic (Clark $\&$ Haskins 1998), in other species (Clark et al. 2001) the two reproductive modes are found in near proximity in the same habitat. Apparently there are forces which maintain this dual occurrence even when there is no obvious selection for different habitats. Of course, the sexual isolates undergo genetic recombination and can thus adapt to a variety of environmental conditions, but the patchy, and often ephemeral, nature of suitable habitats could also require a high dispersal ability and rapid growth. It has been shown, that the successful colonization of a habitat, by a sexual isolate, would require a spore rain 2.4 times that of an asexual isolate (Schnittler \& Tesmer 2008). It has also been shown (Betterley \& Collins 1983) that apogamic isolates of Didymium iridis are generally quicker to form plasmodia and undergo sporulation, and that plasmodial of this species undergo competition under crowded conditions (Clark 1980a, b). Thus, the apogamic strains appear to be adapted to find and quickly exploit scattered and ephemeral habitats, while the sexual isolates maintain a long term ability to exploit a variety of habitats. An ability to switch between modes would seem to provide the species with some advantage; however, this ability seems to be easily lost due to polyploidy and other aberrations that can occur during a number of generations without meiosis (Collins et al. 1983). However, the high level of genetic diversity found between different apogamic isolates (Betterley \& Collins 1983) seems to indicate that either apogamic lines are continually produced at high frequencies from heterothallic lines, and or that there is some type of low level recombination occurring in the apogamic lines, similar to that seen in higher plants (Thompson \& Ritland 2006, van Baarlen et al. 2000).

\section{Acknowledgments}

This review is derived from the research of many investigators of the nuclear reproductive cycle in the myxomycetes. We can only hope that we have done justice to everyone's contribution to this field and have produced a useful summary for future researchers.

\section{References}

Albert M, Therrien CD. 1985 - Cytophotometric evidence of mating fusion competence and its induction in Didymium iridis. Cytobios 44, 189204.

Adler PN, Holt CE. 1975 - Mating type and the differentiated state in Physarum polycephalum. Developmental Biology 43, 240-253.

Aldrich HC. 1967 - Ultrastructure of meiosis in three species of Physarum. Mycologia 59, 127-148.

Aldrich HC. 1969 - The ultrastructure of meiosis in myxamoebae and plasmodia of Physarum flavicomum. American Journal of Botany 56, 290-299.

Aldrich HC, Carroll G. 1971 - Synaptinemal complexes and meiosis in Didymium iridis: a reinvestigation. Mycologia 63, 308-316.

Aldrich HC, Mims CW. 1970 - Synaptinemal 
complexes and meiosis in Myxomycetes. American Journal of Botany 57, 935-941.

Anderson RW, Cooke DJ, Dee J. 1976 Apogamic development in the Myxomycete Physarum polycephalum: A cinematographic analysis. Protoplasma 89, 20-40.

Anderson RW, Truitt CI. 1983. A new type of plasmodial formation in Physarum polycephalum. Genetic Research 42, 285-296.

van Baarlen P, van Dijk PJ, Hoekstra RF, Hans de Jung J. 2000 - Meiotic recombination in sexual diploids and apomictic triploid dandelions (Taraxacum officinale L.). Genome 43, 827-835.

Bailey J. 1995 - Plasmodium development in the myxomycete Physarum polycephalum: genetic control and cellular events. Microbiology 141, 2355-2365.

Bailey J, Anderson RW, Dee J. 1990 Cellular events during sexual development from amoeba to plasmodium in the slime mould Physarum polycephalum. Journal of General Microbiology 136, 739-751.

de Bary A. 1854 - Ueber die Myxomyceten. Botanishe Zeitung 16, 357-369.

Betterley DA, Collins OR. 1983 Reproductive systems, morphology, and genetical diversity in Didymium iridis (Myxomycetes). Mycologia 75, 1044-1063.

Bisby GR. 1914 - Some observations on the formation of the capillitium and the development of Physarella mirabilis Peck and Stemonitis fusca Roth. American Journal of Botany 1, 274288.

Cadman EJ. 1931 - The life history and cytology of Didymium nigripes Fr. Transactions of the Royal Society. Edinburgh 57, 93-142.

Carroll GC, Dykstra R. 1966 - Synaptinemal complexes in Didymium iridis. Mycologia 58, 166-169.

Cayley DM. 1929 - Some observations on Mycetozoa of the genus Didymium. Transactions of the British Mycological Society 14, 227-248.
Cienkowski L. 1863a - Zur Entwickelungsgeschicte der Myxomyceten. für Wissenschaftliche Botanik 3, 325-337.

Cienkowski L. 1863b - Das Plasmodium. Jahrbücher für Wissenschaftliche Botanik 3, 400-441.

Clark J. 1980a - Competition between plasmodial incompatibility phenotypes of the myxomycete Didymium iridis: I. Paired plasmodia. Mycologia 72, 312321.

Clark J. 1980b - Competition between plasmodial incompatibility phenotypes of the myxomycete Didymium iridis: II. Multiple clone crosses. Mycologia 72, 512-522.

Clark J. 1984 - Three-clone Didymium iridis crosses and plasmodial incompatibility phenotype. Mycologia 76, 810-815.

Clark J, Hakim R. 1980 - Nuclear sieving of Didymium iridis plasmodia. Experimental Mycology 4, 17-22.

Clark J, Haskins EF. 1998 - Heterothallic mating systems in the Echinostrelium minutum complex. Mycologia 90, 382388.

Clark J, Haskins EF. 2010 - Reproductive systems in the myxomycetes: a review. Mycosphere 1, 337-367.

Clark J, Haskins EF. 2012 - Plasmodial incompatibility in the myxomycetes: a review. Mycosphere 3, 143-155.

Clark J, Landolt JC. 1993 - Didymium iridis reproductive systems: additions and meiotic drive. Mycologia 85, 764-768.

Clark J, Stephenson SL, Landolt JC. 2001 Biosystematics of the Didymium iridis super species complex: additional isolates. Mycotaxon 79, 447-454.

Collins OR. 1961 - Heterothallism and homothallism in two myxomycetes. American Journal of Botany 48, 674683.

Collins OR. 1963 - Multiple alleles at the incompatibility locus in the myxomycete Didymium iridis. American Journal of Botany 50, 477-480.

Collins OR. 1979 - Myxomycete biosystematics and some recent developments and future research opportunities. Botanical Review 45, 145-201. 
Collins OR. 1980 - Apomictic-heterothallic conversion in a myxomycete, Didymium iridis. Mycologia 72, 11091116.

Collins OR. 1891 - Myxomycete genetics, 1960-1981. Journal of the Elisha Mitchell Society 97, 101-125.

Collins OR, Gong T. 1985 - Genetical relatedness of a former apomicts and a heterothallic isolate in Didymium iridis (Myxomycetes). Mycologia 77, 300307.

Collins OR, Ling H. 1968 - Clonally produced plasmodia in heterothallic isolates of Didymium iridis. Mycologia 60, 858868.

Collins OR, Tang HC. 1988 - Further studies on conversion from non-heterothallism to heterothallism in Stemonitis flavogenita (Myxomycetes, Stemonitales). Mycologia 80, 405-407.

Collins OR, Therrien CD. 1976 Cytophotometric measurement of nuclear DNA in seven heterothallic isolates of Didymium iridis, a Myxomycete. American Journal of Botany 63, 457-463.

Collins OR, Therrien CD, Betterley DA. 1978 - Genetic and cytological evidence for chromosome elimination in a true slime mold, Didymium iridis. American Journal of Botany 65, 660-670.

Collins OR, Gong T, Clark J, Tang HC. 1983a - Apomixis and heterothallism in Stemonitis flavogenita (Myxomycetes, Stemonitales). Mycologia 75, 614-622.

Collins OR, Gong T, Grantham M. 1983b Genetical analysis of an apomicticheterothallic convertant of Didymium iridis (Myxomycetes). Mycologia 75, 683-672.

Conrad HS. 1910 - Spore formation in Lycogala exiguum. Proceedings of the Iowa Academy of Science 17, 83-84.

Cooke DJ, Dee J. 1974 - Plasmodium formation without change in nuclear DNA content in Physarum polycephalum. Genetic Research 23, 317.

Dalleux G. 1940 - Rescerches sur les plasmodes de deux Myxomycètes. Revue de Cytologie et Cytophysiologie
Végétale 4, 123-182.

Dangeard P. 1947 - Notes biologiques et cytologiques sur un Myxomycète (Didymium clavus). Botanishe 33, 3957.

Dee J. 1960 - A mating type system in an acellular slime mould. Nature 185, 780-781.

Gaither T, Collins OR. 1984 - Synaptinemal complexes in an apomictic line of Stemonitis flavogenita (Myxomycetes, Stemonitales). Mycologia 76, 11231125.

Gilbert HC. 1935 - Critical events in the life history of Ceratomyxa. American Journal of Botany 22, 52-74.

Gray W, Alexopoulos CJ. 1968 - Biology of the Myxomycetes. The Ronald Press Company, New York.

Guttes E, Guttes S, Rusch HP. 1961 Morphological observations on growth and differentiation of Physarum polycephalum grown in pure culture. Developmental Biology 3, 588-614.

Guttes E, Guttes S, Ellis RA. 1968 - Electron microscope study of mitosis in Physarum polycephalum. Journal of Ultrastructural Research 22, 508-528.

Harper RA. 1914 - Cleavage in Didymium melanospermum. American Journal of Botany 1, 127-144.

Haskins EF. 1976 - High voltage electron microscopical analysis of chromosome number in the slime mold, Echinostelium mimutum de Bary. Chromosoma 56, 95-100.

Haskins EF, Therrien CD. 1978 - The nuclear cycle of the myxomycete Echinostelium mimtum. 1. Cytophotometric analysis of nuclear DNA of the amoebal and plasmodial phases. Experimental Mycology 2, 32-40.

Haskins EF, Hinchee AA, Cloney RA. 1971 The occurrence of synaptenemal complexes in the slime mold Echinostelium minutum de Bary. Journal of Cell Biology 51, 898-903.

Hinchee AA, Haskins EF. 1980a - Open spindle nuclear division in the amoebal phase of the acellular slime mold Echinostelium minutum with chromosome movement related to 
pronounced rearrangement of spindle microtubules. Protoplasma 102, 117130.

Hinchee AA, Haskins EF. 1980b - Closed spindle nuclear division in the plasmodial phase of the acellular slime mold Echinostelium minutum. Protoplasma $102,235-252$.

Howard FL. 1931 - The life history of Physarum polycephalum. American Journal of Botany 18, 116-133.

Jahn E. 1901 - Myxomycetenstudien. 1. Dictydium umbilicatum Schrader. Berichte der Deutschen Botanischen Gesellschaft 19, 97-115.

Jahn E. 1908 - Myxomycetenstudien, 7. Ceratomyxa. Berichte der Deutschen Botanischen Gesellschaft 26, 342-352.

Jahn E. 1911 - Myxomycetenstudien, 8. Der Sexualakt. Berichte der Deutschen Botanischen Gesellschaft 29, 231-247.

Jahn E. 1933 - Myxomycetenstudien, 15. Somatische und generative Kernteilungen. Berichte der Deutschen Botanischen Gesellschaft $\quad 51, \quad 377-$ 385.

Kerr NS. 1961 - A study of plasmodium formation by the true slime mold Didymium nigripes. Experimental Cell Research 23, 603-611.

Kerr SJ. 1967 - A comparative study of mitosis in amoebae and plasmodia of the true slime mold, Didymium nigripes. Journal of Protozoology 14, 439-445.

Koevenig JL. 1961 - Three educational films on Myxomycetes with a study of the life cycle of Physarum gyrosum Rost. Ph.D. Thesis, University of Iowa, Iowa City.

Koevenig JL. 1964 - Studies on life cycle of Physarum gyrosum and other myxomycetes. Mycologia 56, 170-184.

Kranzlin H. 1907 - Zur Entwicklungsgeschichte der Sporangien bei den Trichen und Arcyrien. Archiv der Protistenkunde 9, 170-194.

Kubbies M, Wick R, Hildebrabdt A, Sauer HW. 1986 - Flow cytometry reveals a high degree of genomic size variation and mixoploidy in various strains of the acellular slime mold Physarum polycephalum. Cytometry 7, 481-485.

Laane MM, Haugli FB. 1976 - Nuclear behavior during meiosis in the myxomycete Physarum polycephalum. Norwegian Journal of Botany 23, 7-21.

Laane M, Haughli FB, Mellem TR. 1976 Nuclear behavior during sporulation and germination in the Colonia strain of Physarum polycephalum. Norwegian Journal of Botany 23, 177-189.

Lister A. 1893 - On the division of nuclei in the Mycetozoa. Journal of the Linnean Society, Botany 29, 529-542.

Martin GW, Alexopoulos CJ. 1969 - The Myxomycetes. University of Iowa Press, Iowa City.

Maynard Smith J. 1978 - The Evolution of Sex. Cambridge University Press, Cambridge.

McCullough CHR, Cooke DJ, Foxon SL, Sudbery PE, Grant WD. 1973 Nuclear DNA content and senescence in Physarum polycephalum. Nature New Biology 243, 263-265.

McGuinness MD, Haskins EF. 1985 - Genetic analysis of the reproductive system of the true slime mold Comatricha lurida. Mycologia 77, 646-653.

McManus MA. 1958 - In vivo studies of plasmogamy in Ceratiomyxa. Bulletin of the Torrey Botanical Club 85, 28-37.

McManus MA. 1961 - Culture of Stemonitis fusca on glass. American Journal of Botany 48, 582-588.

Mogie M. 1986 - Automixis: its distribution and status. Biological Journal of the Linnean Society 28, 321-329.

Mohberg J. 1977 - Nuclear DNA content and chromosome numbers throughout the life cycle of the Colonia strain of the myxomycete Physarum polycephalum. Journal of Cell Science 24, 95-108.

Moses MJ, Coleman JR. 1964 - Structural patterns and the functional organization of chromosomes. In Locke M. (ed.) Second symposium for the study of Development and Growth. Academic Press, New York.

Mulleavy P. 1979 - Genetic and cytological studies in heterothallic and nonheterothallic isolates of the myxomycete Didymium iridis. Ph.D. Disserta- 
tion, University of California, Berkley.

Mulleavy P, Collins OR. 1979 - Development of apogamic amoebae from heterothallic lines of a myxomycete, Didymium iridis. American Journal of Botany 66, 1069-1073.

Mulleavy P, Collins OR. 1981 - CIPC-induced and spontaneously produced diploid myxamoebae in a myxomycete, Didymium iridis: a study of mating-type heterozygotes. Mycologia 73, 62-77.

Nader WF, Shipley GL, Huttermann A, Holt CE. 1984 - Analysis of an inducer of the amoebal-plasmodial transition in the Myxomycetes Didymium iridis and Physarum polycephalum. Developmental Biology 103, 504-510.

Olive EW. 1907 - Cytological studies on Ceratomyxa. Transactions of the Wisconsin Academy of Science 15, 753-773.

Pallotta DJ, Youngman PJ, Shinnick TM, Holt CE. 1979 - Kinetics of mating in Physarum polycephalum. Mycologia 71, 68-84.

Poulter RTM, Honey NK. 1977 - Genetic analysis of a cross between two homothallic strains of Physarum polycephalum. Genetic Research 29, $55-63$.

Prowazek S. 1904 - Kernveränderung in Myxomycetenplasmodien.

Oesterrichische Botanische Zeitschrift 54, 278-281.

Rosen F. 1893 - Beitrage zur Kenntniss der Pflanzenzellen. II. Studien über die Kerne und die Membranbildung bei Myxomyeten und Pilze. Beiträge zur Biologie die Pflanzen 6, 237-266.

Ross IK. 1957 - Syngamy and plasmodial formation in the Myxomycetes. American Journal of Botany 44, 843850.

Ross IK. 1960 - Sporangial development in Lamprodrma arcyrionema. Mycologia 52, 621-627.

Ross IK. 1961 - Further studies on meiosis in the Myxomycetes. American Journal of Botany 48, 244-248.

Ross IK. 1967a - Syngamy and plasmodial formation in the Myxomycete Didymium iridis. Protoplasma 64, 104-119.
Ross IK. 1967b - Growth and development of the myxomycete Perichaena vermincularis. II. Chromosme numbers and nuclear cycles. American Journal of Botany 54, 1231-1236.

Ross IK, Cummings RJ. 1970 - An unusual pattern of multiple cell and nuclear fusions in the heterokaryotic slime mold Didymium iridis. Protopasma 70, 281- 294.

Ross IK, Shipley GL. 1973 - Sexual and somatic fusion in the heterothallic slime mold Didymium iridis 2. Effects of actinomycin D, cyclohexamide and lysosome stabilizers. Microbios 7, 165171.

Sansome ER, Dixon PA. 1965 - Cytological studies of the myxomycete Ceratiomyxa fruticulosa. Archiv für Mikrobiologie 52, 1-9.

Sansome ER, Sansome FW. 1961 Observations on Ceratiomyxa in West Africa. Journal of the West African Science Association 7, 93-100.

Schnittler M, Tesmer J. 2008 - A habitat colonization model for spore-dispersal organisms - does it work with eumycetozoans? Mycological Research 112, 697-707.

Schünemann E. 1930 - Untersuchungen über die Sexualitat der Myxomyceten. Planta 9, 645-672.

Schure PSJ. 1949 - Nuclear division in the fructifications of some Myxomycetes and a method of culture to obtain fructifications. Antonie van Leeuwenhock Journal of Microbiology and Serology 15, 143-161.

Schuster F. 1964 - Electron microscope observations on spore formation in the true slime mold Didymium nigripes. Journal of Protozoology 11, 207-216

Sherman JD, Mims CW. 1985 Ultrastructural evidence for meiosis in a nonheterothallic isolate of the myxomycete Didymium iridis. Mycologia 77, 328-332.

Shipley GL, Holt CE. 1982 - Cell fusion competence and its induction in Physarum polycephalum and Didymium iridis. Developmental Biology 90, 110117. 
Skupienski FX. 1926a - Sur le cycle évoltif chez une espèce de myxomycète endosporée. Comptes Rendus de l'Académie des Sciences 182, 150-152.

Skupienski FX. 1926b - Sur le cycle évoltif chez une espèce de myxomycète endosporée Didymium difforme. Etude cytologique. Comptes Rendus de l'Académie des Sciences 184, 134114344.

von Stosch HA. 1935 - Sexualität und Apogamie bei Didymiiaceen. Planta 23, 623-656.

von Stosch HA. 1937 - Über den Generationwechsel der Myxomyceten, eine Erwiderung. Berichte der Deutsch Botanischen Gesellschaft 55, 362-369.

Strasburger E. 1884 - Zur Entwickelungsgeschichte der Sporangien von Trichia fallax. Botanische Zeitung 42, 305326.

Therrien CD. 1966 - Microspectrophotometric measurement of nuclear deoxyribonucleate acid in two Myxomycetes. Canadian Journal of Botany 44, 16671675.

Therrien CD, Collins OR. 1976 - Apogamic induction of haploid plasmodia in a myxomycete, Didymium iridis. Developmental Biology 49, 283-287.

Therrien CD, Haskins EF. 1981 - The nuclear cycle of the myxomycete Echinostelium mimtum. II. Cytophotometric analysis of the nuclear DNA content of the sporangial phase. Mycology 2, 229-235.

Therrien CD, Yemma JJ. 1974 - Comparative measurements of nuclear DNA in a heterothallic and a self-fertile isolate of the myxomycete, Didymium iridis.
Mycosphere Doi 10.5943/mycosphere/4/2/6

Ame-rican Journal of Botany 61, 400404.

Therrien CD, Bell WR, Collins OR. 1977 Nuclear DNA content of myxamoebae and plasmodia in six non-heterothallic isolates of a myxomycete, Didymium iridis. American Journal of Botany 64, 286-291.

Thompson SL, Ritland K. 2006 - A novel mating system analysis for modes of self-oriented mating applied to diploid and polyploidy Easter daisies (Townsendia hookeri). Heredity 97, 119-126.

Wilson CM, Cadman EJ. 1928 - The life history and cytology of Reticularia lycoperdon. Transactions of the Royal Society Edinburgh 55, 555-608.

Wilson CM, Ross IK. 1955 - Meiosis in the Myxomycetes. American Journal of Botany 42, 743-749.

Wollman C. 1966 - Cultural studies of selected species of Myxomycetes. Ph.D. Dissertation, University of Texas, Austin.

Yemma JJ, Therien CD. 1972 - Quantitative micro-spectrophotometry of nuclear DNA in selfing strains of the myxomycete Didmium iridis. American Journal of Botany 59, 823-835.

Yemma JJ, Therrien CD, Jukupcin GJ. 1980 Isolation of haploid clones bearing a mating type allele from a diploid apomictic isolate of Didymium iridis. Cytobios 29, 145-157.

Youngman PJ, Adler PN, Shinnick TM, Holt CE. 1977 - An extracellular inducer of asexual plasmodial formation in Physarum polycephalum. Proceedings of the National Academy of Sciences USA 74, 1120-1124. 